\title{
Effects of Spinning Conditions on Properties of Polyester Yarn Prepared using an Ultra-high-speed Melt Spinning Technique Equipped with a Steam Chamber
}

\author{
Yo-Seung Ho, Hak-Yong Kim, ${ }^{*}$ Fan-Long Jin, ${ }^{\dagger}$ and Soo-Jin Park ${ }^{\ddagger},{ }^{*}$ \\ Department of Textile Engineering, Chonbuk National University, Chonju 560-756, Korea \\ "E-mail:khy@chonbuk.ac.kr \\ ${ }^{\dagger}$ School of Chemical and Materials Engineering, Jilin Institute of Chemical Technology, Jilin City 132022, P. R. China \\ ${ }^{\ddagger}$ Department of Chemistry, Inha University, Incheon 402-751, Korea. ${ }^{*}$ E-mail: sjpark@inha.ac.kr \\ Received June 12, 2010, Accepted September 14, 2010
}

\begin{abstract}
In this study, the effects of the various parameters of spinning and drawing processes on the properties of polyester full drawn yarn (FDY) prepared by steam processing during high-speed spinning were investigated using several techniques. The wet shrinkage ratio of the FDY was able to be manipulated by controlling the temperature and draw ratio. The FDY made using the steam high speed spinning technique exhibited identical properties (such as tenacity, elongation, and wet shrinkage ratio) to that of regular FDY, made using the spin-draw process. FDY prepared using the steam process during high-speed spinning showed excellent dyeability. The dye pick-up of the polyester yarn spun at high-speed spinning was found to be improved when dyed under an atmospheric pressure of $100{ }^{\circ} \mathrm{C}$. This result was the same as regular FDY dyed under a high pressure of $130{ }^{\circ} \mathrm{C}$.
\end{abstract}

Key Words: Polyester, Full drawn yarn, Wet shrinkage ratio, Tenacity, Elongation

\section{Introduction}

In general, fiber formation methods can be divided according to spinning forms: fusion spinning, dry spinning, wet spinning, and dry-wet spinning. Among these, fusion spinning is the simplest process for thermoplastic resins. ${ }^{1}$

Recently, high-speed spinning has received substantial attention from two viewpoints: improved productivity in industry and the altered physical properties of fibers. Much of the recent research in this field has been concerned with the structure of poly (ethylene terephthalate) (PET) fibers spun using fusion spinning and a spinning speed above $5000 \mathrm{~m} / \mathrm{min}$. Researchers have studied the phenomenon of high-speed spinning and the changes in fiber structure which result from it. ${ }^{2-9}$ High-speed spinning is distinguished by two traits: the crystallization promoted by macromolecule orientation and a necking phenomenon which occurs during spinning. ${ }^{2-5}$ In early studies in this field, Penning et al. first investigated the orientation crystallization of the macromolecule. Their research focused on the morphology of the macromolecule and crystallization dynamics in the orientation crystallization. ${ }^{6-9}$

Ultra-high-speed melt spinning is a field of fusion spinning which prepares the structurally advanced fibers from orientation crystallization of macromolecule at high speed and high extension. In the spinning process, macromolecule orientation and orientation-induced crystallization form simultaneously under a high extension stress. This method can produce fibers that have excellent physical properties without using elongation and heat treatment processes. ${ }^{10}$

In this study, polyester full-drawn yarn (FDY) was prepared using an ultra-high-speed melt spinning technique, and the effects of spinning conditions on the properties of fibers were investigated using several techniques.

\section{Experimental}

Materials. Terephtalic acid (TPA), isophthalic acid, and ethylene glycol used in this study were purchased from Aldrich. Antimony trioxide and trimethyl phosphate were used as a catalyst and antioxidant, respectively, and were also supplied by Aldrich. The copolyester was synthesized according to a method reported in a previous work. ${ }^{9}$

Synthesis of copolyester. Terephthalic acid (166.1 g, $1 \mathrm{~mol})$, isophthalic acid (5.0 g, $0.03 \mathrm{~mol})$, and ethylene glycol (63.4 g, $1.03 \mathrm{~mol}$ ) were placed in a $500 \mathrm{~mL}$ reactor equipped with a mechanical stirrer, thermometer sensor, and reflux condenser. The mixture was gradually heated to $200{ }^{\circ} \mathrm{C}$ and reacted for $3 \mathrm{~h}$. Antimony trioxide $(2 \mathrm{~g})$ and trimethyl phosphate $(1 \mathrm{~g})$ were added to the mixture, which was gradually heated to $270^{\circ} \mathrm{C}$ and reacted for $2 \mathrm{~h}$. Finally, chip-type melting materials were obtained (yield: 91.3\%). Mn: 15000 g/mol, PDI: 1.09. FT-IR (KBr; $v$, $\left.\mathrm{cm}^{-1}\right): 2970(\mathrm{CH}), 1725(\mathrm{C}=\mathrm{O}), 1638(\mathrm{C}=\mathrm{C}), 1620(\mathrm{C}=\mathrm{C}), 1190$ (C-O-C), 1062 (C-H), 988 (CH).

High-speed polyester FDY spinning. The high-speed polyester FDY was prepared using an ultra-high-speed melt spinning technique equipped with a steam chamber at spinning speeds ranging from 3000 to $6500 \mathrm{~m} / \mathrm{min}$, a drawing ratio of 5800 $\mathrm{m} / \mathrm{min}$, and steam pressures ranging from 5 to $10 \mathrm{~kg} / \mathrm{cm}^{2}$. See Table 1 for a list of spinning temperatures.

Characterization and measurements. The melting tempera-

Table 1. Ultra-high speed spinning conditions for polyester FDY

\begin{tabular}{cccccccc}
\hline & \multicolumn{3}{c}{ Extruder zone } & \multicolumn{4}{c}{ Line and steaming box } \\
\hline Part & A & B & C & D & Line & Beam & Hood \\
Temperature $\left({ }^{\circ} \mathrm{C}\right)$ & 270 & 280 & 285 & 290 & 290 & 290 & 230 \\
\hline
\end{tabular}


ture and heat of fusion of the samples were measured with a differential scanning calorimeter (Perkin-Elmer DSC-7) at a heating rate of $10^{\circ} \mathrm{C} / \mathrm{min}$ and in a temperature range from 30 to $350{ }^{\circ} \mathrm{C}$ under a nitrogen atmosphere.

A 5\% alkali aqueous solution was heated to its boiling point, and then a round sample was added to this solution. The solution was stirred, washed with distilled water, and finally dried in a vacuum oven. The weight loss of the sample was calculated by the following equation.

$$
\text { Weight loss }(\%)=\frac{\left(W_{0}-W_{1}\right)}{W_{0}}
$$

where $W_{0}$ and $W_{l}$ are the weight of the sample before and after alkali treatment, respectively.

The fibers were shaped into a hoop form and hung on a $0.7 \mathrm{~g}$ clip, and then the length $\left(\mathrm{L}_{1}\right)$ of the hoop was measured. The hoop was placed in a glass tube in a damp contraction percentage measurement device and dipped at $100 \pm 1{ }^{\circ} \mathrm{C}$ for $30 \mathrm{~min}$. The hoop was taken out of the tube, and after $2 \mathrm{~h}$, the length $\left(\mathrm{L}_{2}\right)$ of the hoop was measured. The shrinkage was calculated according to the following equation.

$$
\text { Wet shrinkage ratio }(\%)=\frac{L_{1}-L_{2}}{L_{1}} \times 100
$$

A tensile test was conducted using an Instron mechanical tester (Fafegraph-M and Textecho Co., Germany) at a temperature of $25{ }^{\circ} \mathrm{C}$ and a relative humidity of $65 \%$. The specimen length was $100 \mathrm{~mm}$ and the tensile speed was $200 \mathrm{~mm} / \mathrm{min}$. All mechanical property values were obtained by averaging ten experimental values.

The birefringence was measured using a polarization microscope (Zeiss, Germany). The angle between the fiber and the polarized light ruler was $45^{\circ}$, and the light wavelength was 546 $\mathrm{mm}$. The birefringence was calculated using the following equations:

$$
\begin{gathered}
R=\frac{\theta \times \lambda}{180} \\
\Delta n=\frac{R}{d}
\end{gathered}
$$

where $R$ is the natural value, $\lambda$ is the wavelength, $\theta$ is the rotation angle of the analyzer, and $d$ is the thickness of the specimen.

The density of the specimen was measured using a density grade tube (Shibayama density gradient column, Japan) using carbon tetrachloride (density: 1.59)/hexane (density: 0.68) as a mixture solvent at $23{ }^{\circ} \mathrm{C}$.

To evaluate the dyeing quality, Lumacron Black SE-3G was used as a dye. A $2 \%$ dye (fiber weight was used as a base) was diluted to a liquid ratio of $1: 20$. The samples were dyed at $100{ }^{\circ} \mathrm{C}$ for $30 \mathrm{~min}$ and then washed with distilled water at $80^{\circ} \mathrm{C}$ for 10 $\min$. The surface color difference $(\mathrm{K} / \mathrm{S})$ of the samples was calculated using equation (6). ${ }^{11}$

$$
\frac{K}{S}=\frac{(1-R)^{2}}{2 R}
$$

where $R$ is reflexibility, $K$ is the light absorption, and $S$ is the scattered coefficient at a given wavelength.

\section{Results and Discussion}

Effects of spinning conditions. Figure 1 shows the effects of spinning conditions, namely, tenacity, elongation, birefringence, wet shrinkage, density, crystallinity, heat of fusion during melting $\left(\Delta \mathrm{H}_{\mathrm{m}}\right)$, and heat of fusion during cooling $\left(\Delta \mathrm{H}_{\mathrm{c}}\right)$, on the properties of polyester FDY. As seen in Figure 1, tenacity increased and elongation decreased with increasing spinning speed. The values of wet shrinkage, crystallinity, $\Delta \mathrm{H}_{\mathrm{m}}$, and $\Delta \mathrm{H}_{\mathrm{c}}$ varied significantly at a spinning speed of about $4000 \mathrm{~m} / \mathrm{min}^{12}$ These results demonstrate the importance of process factors that control fiber microstructure above $4000 \mathrm{~m} / \mathrm{min}$.

Figure 2 shows the tenacity, elongation, Young's modulus, birefringence, and wet shrinkage ratio of polyester FDY as a function of spinning temperature. Tenacity did not significantly vary with increasing spinning temperature. When the spinning temperature was increased, elongation increased, and Young's modulus and birefringence decreased. These results indicate that the crystal size varied with decreasing internal crystallinity. ${ }^{13,14}$

The wet shrinkage ratio increased as the spinning temperature was increased up to $300{ }^{\circ} \mathrm{C}$, which was due to the reduced orientation and crystallinity. Conversely, the wet shrinkage ratio decreased when the temperature rose above $300{ }^{\circ} \mathrm{C}$. This can be attributed to the decomposition of polyester, which results in a polyester with a lower molecular weight.

Table 2 shows tenacity, elongation, and shrinkage as functions of the draw ratio. As shown in the table, tenacity decreased and elongation increased when the draw ratio was decreased or the first godet roller $(\mathrm{G} / \mathrm{R})$ speed was increased. These results can be attributed to variation in the internal crystal size, the degree of molecule chain orientation, and the crystals in the amorphous region inside the fibers. The wet shrinkage did not vary significantly with a draw ratio decreasing to 1.478 , below which it dropped suddenly.

Figure 3 shows the thermal properties of high-speed polyester FDY prepared by on-line steam treatment as a function of the first G/R speed. As can be seen, the melting point shifted to higher temperatures as the first $\mathrm{G} / \mathrm{R}$ speed increased. This can be attributed to the increase in spinning stress with increasing first G/R speed, which increased the internal crystal structure density of the fiber. ${ }^{12}$ The fusion heat increased with increasing $1 \mathrm{st} \mathrm{G} / \mathrm{R}$ speed up to $4100 \mathrm{~m} / \mathrm{min}$, and it exhibited a constant value up to $5000 \mathrm{~m} / \mathrm{min}$, beyond which it decreased.

Figure 4 shows the effect of the draw ratio on the weight reduction of high-speed polyester FDY treated with $\mathrm{NaOH}$ solution. The weight reduction increased as the first G/R speed and treatment time were increased. The crystallinity also increased with increasing first $\mathrm{G} / \mathrm{R}$ speed. In contrast, the orientation degree decreased as the draw ratio decreased, and the molecule chain density in the amorphous region was decreased by 

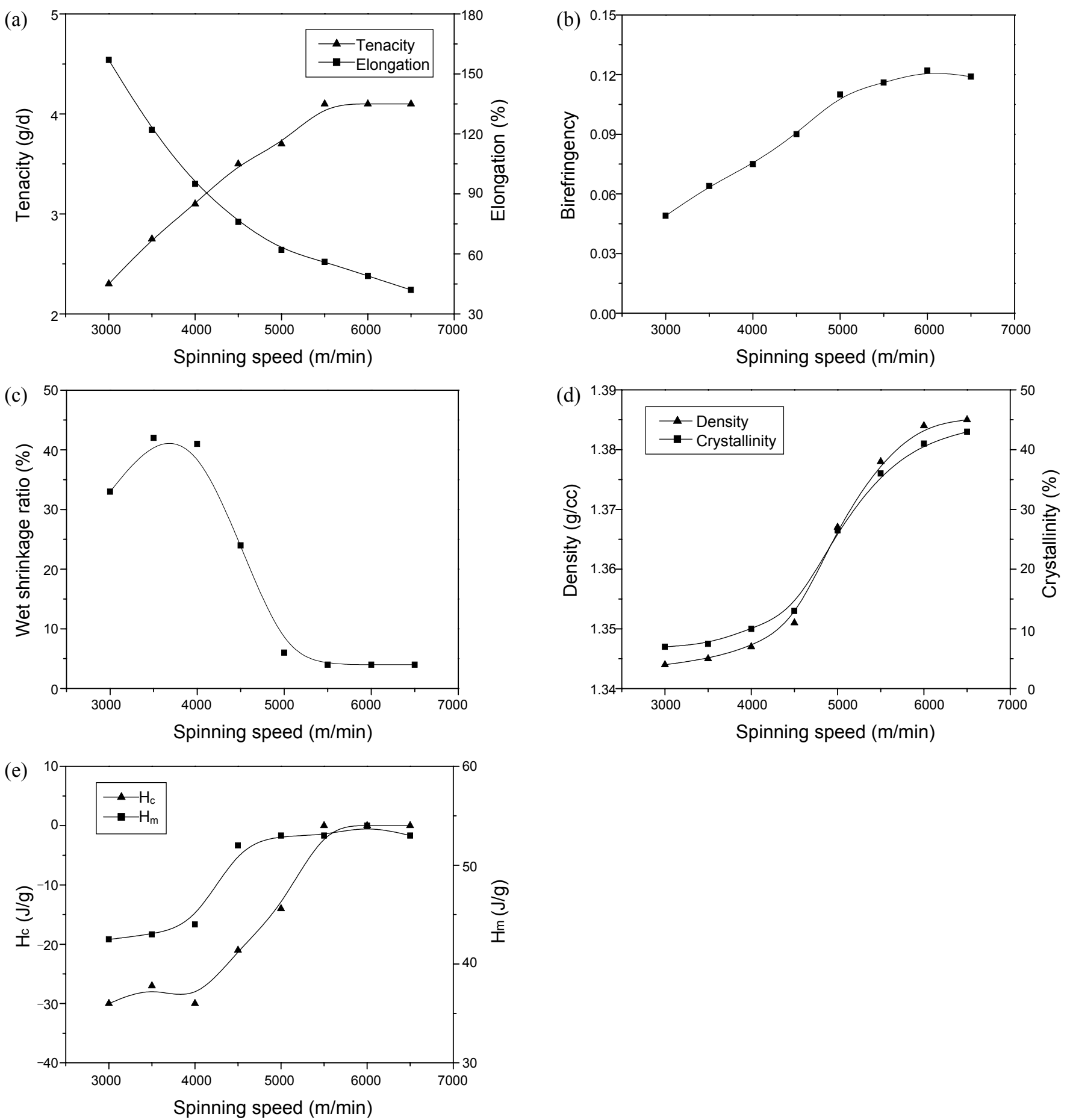

Figure 1. Tenacity and elongation (a), birefringence (b), wet shrinkage ratio (c), density and crystallinity (d), and thermal properties of polyester FDY as a function of spinning speed.

hydrolysis of alkali. Thus, the internal amorphous region of the fiber was easily infiltrated, which allowed the transfer by hydrolysis to occur with ease.

Properties of polyesteryams prepared by the ultra-high-speed melt spinning technique. Table 3 shows the physical properties of polyester FDY produced with steam pressure ranging from 5 to $10 \mathrm{~kg} / \mathrm{cm}^{2}$. As shown in the table, tenacity increased and shrinkage decreased with increasing steam pressure. These results are similar to those of regular FDY prepared using the G/R heat treatment method, where the shrinkage decreased as the heat treatment temperature was increased. The results indicate that the shrinkage range of polyester FDY can be controlled with the use of steam pressure.

Figure 5 shows the weight reduction of polyester FDY prepared by spin-draw, on-line steaming, and the highly oriented yarn (HOY) process. The weight reduction of polyester FDY prepared by the spin-draw process was the lowest, while that of polyester FDY prepared by the HOY process was the highest 
(a)
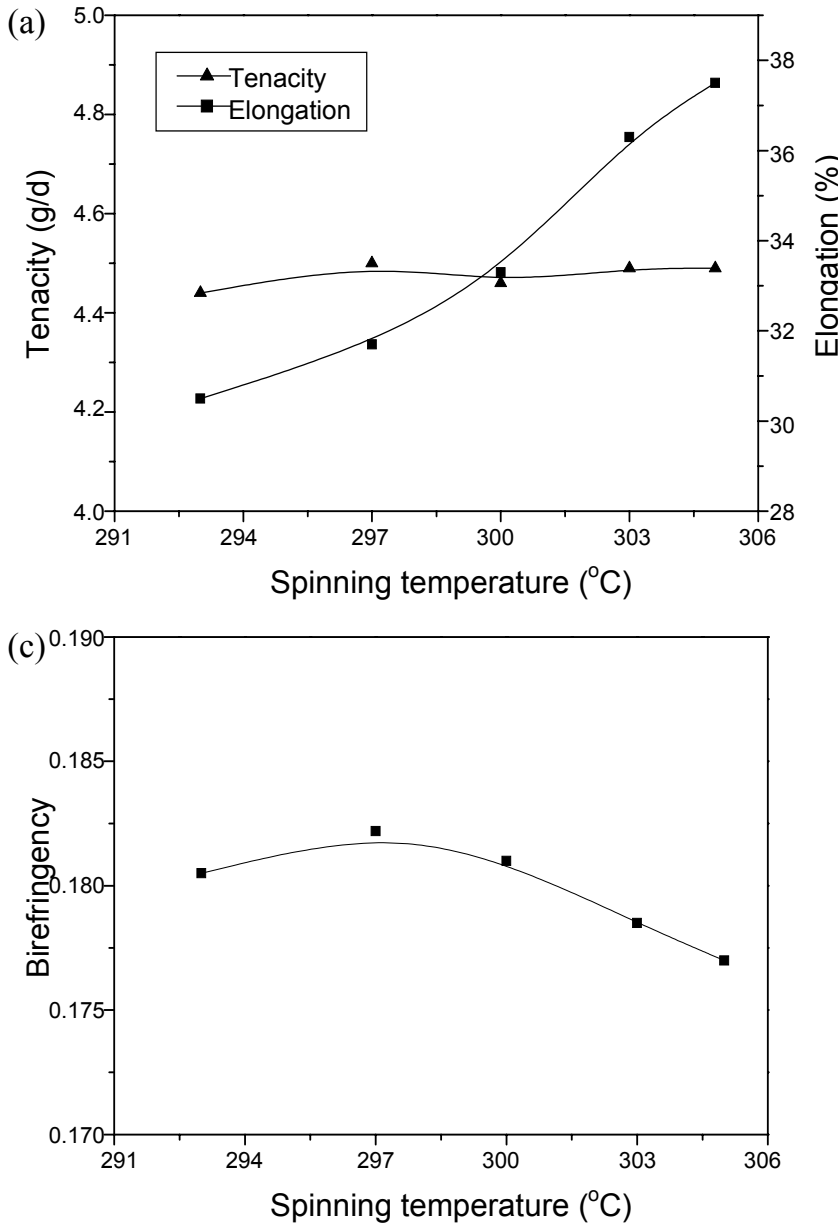
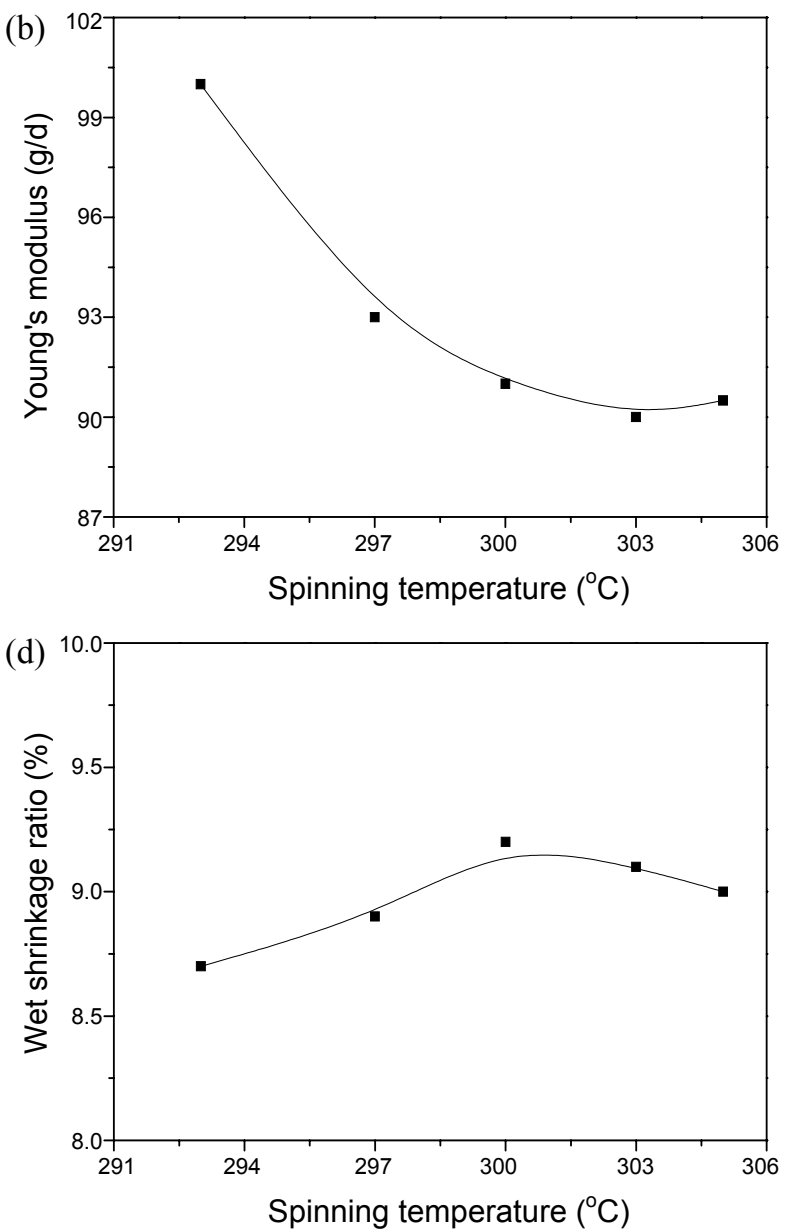

Figure 2. Tenacity and elongation (a), Young's modulus (b), birefringency (c), and wet shrinkage ratio of polyester FDY as a function of spinning temperature.

Table 2. Results from ultra-high speed polyester FDY as a function of 1 st G/R speed and drawing conditions

\begin{tabular}{|c|c|c|c|c|c|c|c|c|}
\hline & \multicolumn{2}{|c|}{ G/R speed (m/min) } & \multirow{2}{*}{$\begin{array}{l}\text { Winder speed } \\
\qquad(\mathrm{m} / \mathrm{min})\end{array}$} & \multirow{2}{*}{ Draw ratio } & \multicolumn{3}{|c|}{ Properties } & \multirow{2}{*}{ Yarn quality } \\
\hline & First G/R & Second G/R & & & Tenacity (g/d) & Elongation (\%) & Shrinkage (\%) & \\
\hline $\mathrm{T}-1$ & 3000 & 6100 & 5800 & 2.033 & 4.55 & 29.44 & 18.47 & $x$ \\
\hline $\mathrm{T}-2$ & 3500 & 6120 & 5800 & 1.749 & 4.72 & 28.47 & 18.46 & $\times$ \\
\hline $\mathrm{T}-3$ & 4100 & 6060 & 5800 & 1.478 & 4.67 & 27.50 & 17.55 & $\triangle$ \\
\hline $\mathrm{T}-4$ & 4500 & 6100 & 5800 & 1.356 & 4.92 & 28.20 & 10.91 & $\triangle$ \\
\hline $\mathrm{T}-5$ & 5000 & 6150 & 5800 & 1.230 & 4.75 & 36.23 & 7.85 & $\bigcirc$ \\
\hline $\mathrm{T}-6$ & 5500 & 6150 & 5800 & 1.118 & 4.54 & 42.87 & 4.73 & $\bigcirc$ \\
\hline $\mathrm{T}-7$ & 5500 & 6470 & 6080 & 1.176 & 4.61 & 35.96 & 5.64 & $\bigcirc$ \\
\hline $\mathrm{T}-8$ & 5350 & 6380 & 6000 & 1.187 & 4.77 & 37.67 & 7.37 & $\bigcirc$ \\
\hline
\end{tabular}

Note: $\times$-bad; $\triangle$-average; $\bigcirc$-good.

under the same conditions. This result can be attributed to the high degree of crystal orientation of polyester FDY prepared using the spin-draw process. The polyester FDY prepared by the HOY process had a high crystal degree and a low degree of orientation in the amorphous region; thus, alkali hydrolysis easily occurred, resulting in a greater weight reduction.

Table 4 shows the properties and quality of the high-speed polyester FDY prepared using on-line steam treatment under each processing condition. The amount of fluff showed a stabilized result up to a draw ratio of $6100 \mathrm{~m} / \mathrm{min}$, beyond which it increased suddenly. The loop occurrence increased as the first $\mathrm{G} / \mathrm{R}$ speed was increased. The amount of fluff decreased and the loop occurrence increased with a decraesing draw ratio. Table 5 lists defect features and ways to improve each method. From these results, it is clear that cooling air, oil scattering, and evenness are important factors in reducing the occurrence of 


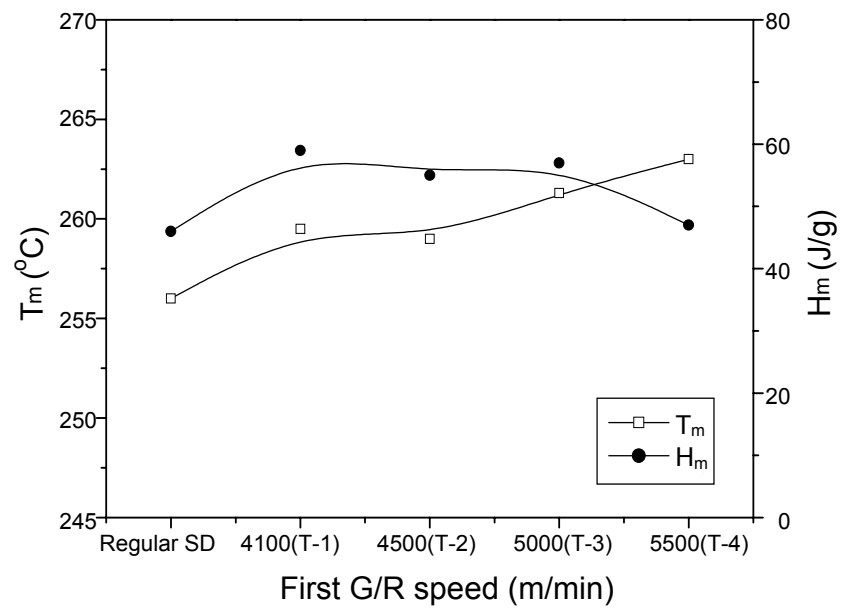

Figure 3. Thermal properties of high-speed polyester FDY prepared by on-line steam treatment as a function of first G/R speed.

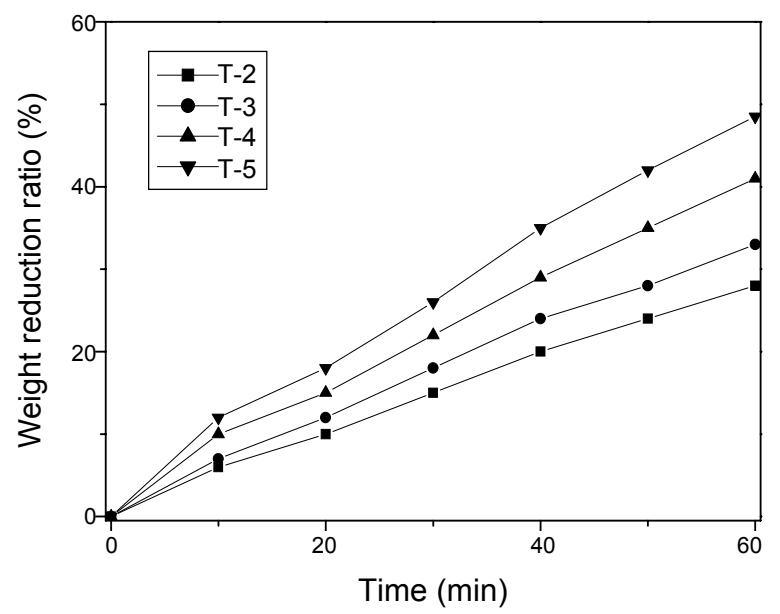

Figure 4. Effect of draw ratio on weight reduction of high-speed polyester FDY treated with $\mathrm{NaOH}$ solution.

Table 3. Effect of steam pressure on properties of polyester FDY

\begin{tabular}{|c|c|c|c|c|c|c|c|c|}
\hline & \multicolumn{2}{|c|}{$\mathrm{G} / \mathrm{R}$ speed $(\mathrm{m} / \mathrm{min})$} & \multirow{2}{*}{$\begin{array}{l}\text { Winder speed } \\
(\mathrm{m} / \mathrm{min})\end{array}$} & \multirow{2}{*}{ Draw ratio } & \multirow{2}{*}{$\begin{array}{l}\text { Steam pressure } \\
\qquad\left(\mathrm{kg} / \mathrm{cm}^{2}\right)\end{array}$} & \multicolumn{3}{|c|}{ Properties } \\
\hline & First G/R & Second G/R & & & & Tenacity (g/d) & Elongation (\%) & Shrinkage (\%) \\
\hline $\mathrm{T}-1$ & & & & & 5 & 4.71 & 35.38 & 6.82 \\
\hline $\mathrm{T}-2$ & 5375 & 6465 & 6100 & 1.203 & 8 & 4.81 & 34.87 & 6.11 \\
\hline $\mathrm{T}-3$ & & & & & 10 & 4.84 & 35.37 & 5.91 \\
\hline
\end{tabular}

fluff in ultra-high-speed spinning of polyester FDY.

Table 6 shows the correlation of spinning tension and oil scattering as a function of first G/R speed. As shown in the table, the spinning tension increased as the first $G / R$ speed was increased. In addition, the tension deviation between the spinning ends increased and the degree of oil scattering decreased above $5500 \mathrm{~m} / \mathrm{min}$.

Figure 6 shows the K/S value of ultra-high-speed polyester FDY prepared by on-line steam treatment as a function of spinning speed. As shown in the figure, the K/S value of high-speed polyester FDY is higher than that of regular SDY. The tension applied to the polyester FDY spun at ultra-high speed increased, and relatively large crystals formed, resulting in an increase in the degree of adsorption of pigments. The K/S value of ultrahigh-speed polyester FDY increased with increasing first $G / R$ speed up to $5000 \mathrm{~m} / \mathrm{min}$.

Figure 7 shows the crystallinity of polyester FDY prepared

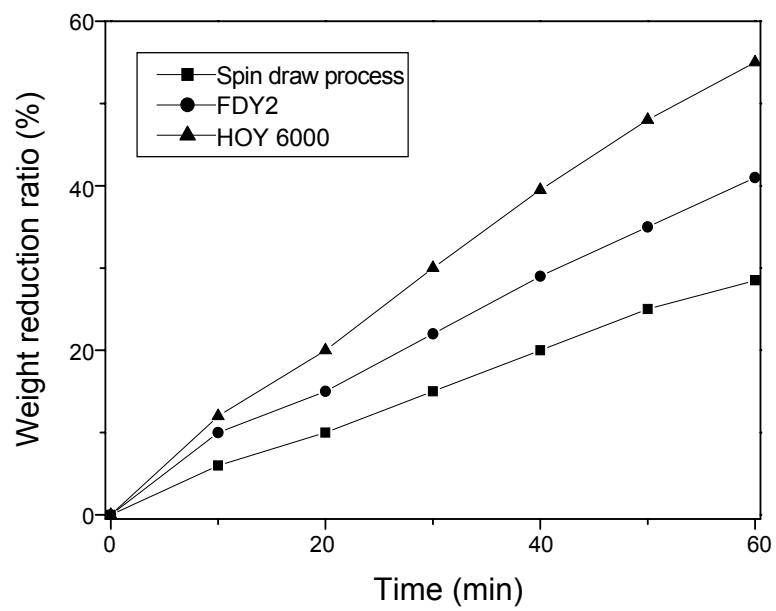

Figure 5. Effect of process conditions on weight reduction of polyester FDY treated with $\mathrm{NaOH}$ solution.

Table 4. Properties and qualities of the high-speed polyester FDY prepared by on-line steam treatment in each process condition

\begin{tabular}{|c|c|c|c|c|c|c|c|c|c|}
\hline \multirow[b]{2}{*}{ Code } & \multicolumn{2}{|c|}{ G/R speed (m/min) } & \multirow{2}{*}{$\begin{array}{l}\text { Draw } \\
\text { ratio }\end{array}$} & \multirow{2}{*}{$\begin{array}{l}\text { Winder speed } \\
(\mathrm{m} / \mathrm{min})\end{array}$} & \multicolumn{3}{|c|}{ Properties } & \multicolumn{2}{|r|}{ Quality } \\
\hline & First & Second & & & $\begin{array}{c}\text { Tenacity } \\
(\mathrm{g} / \mathrm{d})\end{array}$ & $\begin{array}{c}\text { Elongation } \\
(\%)\end{array}$ & $\begin{array}{c}\text { Shrinkage } \\
(\%)\end{array}$ & $\begin{array}{c}\text { No. of } \\
\text { fluff }(e a)^{a}\end{array}$ & Type of fluff ${ }^{b}$ \\
\hline FDY1 & 5000 & 6150 & 1.230 & 5800 & 4.54 & 36.23 & 7.85 & 3 & Broken filament \\
\hline FDY2 & 5000 & 6470 & 1.294 & 6100 & 4.85 & 31.35 & 9.21 & 4.5 & Broken filament \\
\hline FDY3 & 5500 & 6450 & 1.173 & 6080 & 5.08 & 39.72 & 6.50 & 4.8 & Loop \\
\hline FDY4 & 5500 & 6780 & 1.233 & 6400 & 4.94 & 35.18 & 8.95 & 11.3 & Broken filament \\
\hline FDY5 & 5700 & 6430 & 1.184 & 6430 & 4.89 & 34.21 & 7.34 & 27.8 & Broken filament, loop \\
\hline
\end{tabular}

Note: ${ }^{a}$ Number of fluff: total number of fluffs during 1,000,000 m warping procedure on sectional warping mechine. ${ }^{b}$ Type of fluff: feature of fluff observed on the side of package or detected during warping procedure. 
Table 5. Evaluation of pilling behaviors

\begin{tabular}{lcccl}
\hline & Feature of defects & Influence of win-up & Effect & Improvement method \\
\hline Non-uniform of quenching & Loop & High & Low & $\begin{array}{l}\text { - Control of air velocity } \\
\text { - Change of quench chamber }\end{array}$ \\
Non-uniform of oil pick-up & Loop & High & Middle & $\begin{array}{l}\text { - Change of component } \\
\text { - Control of oil pick-up }\end{array}$ \\
Non-uniform of yarn guide & Yarn break and loop & Low & Low & $\begin{array}{l}\text { - Change of guide contact } \\
\text { - Change of guide type }\end{array}$ \\
Non-uniform of draw ratio & Yarn break & High & High & - Re-set of draw ratio
\end{tabular}

Table 6. Correlation of spinning tension and oil scattering as a function of first $\mathrm{G} / \mathrm{R}$ speed

\begin{tabular}{ccc}
\hline $\begin{array}{c}\text { First godet speed } \\
(\mathrm{m} / \mathrm{min})\end{array}$ & $\begin{array}{c}\text { Spinning tension } \\
(\mathrm{cN})\end{array}$ & $\begin{array}{c}\text { Degree of oil } \\
\text { scattering }\end{array}$ \\
\hline 3000 & $19.8 \sim 20.0$ & Good \\
4000 & $20.4 \sim 21.6$ & Good \\
4500 & $22.6 \sim 25.5$ & Good \\
5000 & $33.5 \sim 37.6$ & Bad \\
5500 & $35.0 \sim 45.3$ & Bad \\
6000 & $38.2 \sim 56.2$ & Much bad \\
\hline
\end{tabular}

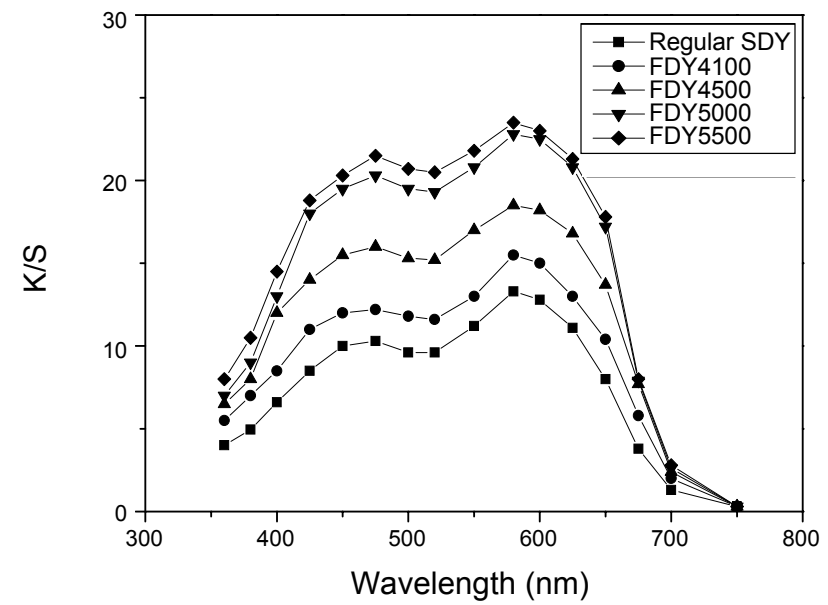

Figure 6. K/S value of high speed polyester FDY prepared by on-line steam treatment as a function of spinning speed.

at various first $\mathrm{G} / \mathrm{R}$ speeds. The crystallinity of polyester FDY increased as the first $\mathrm{G} / \mathrm{R}$ speed was increased. Conversely, the $\mathrm{K} / \mathrm{S}$ value of ultra-high-speed polyester FDY did not increase significantly above $5000 \mathrm{~m} / \mathrm{min}$. When the winder speed was constant and the first $\mathrm{G} / \mathrm{R}$ speed was increased, the spinning tension increased and the crystallinity also increased, whereas the degree of molecular orientation in the amorphous region decreased. Thus, the permeation of the dye did not increase. ${ }^{16}$

The absorption behavior of polyester FDY was investigated by measuring the dye pick-up rate, and the results are shown in Figure 8. The dye pick-up rate of FDY produced by on-line steam processing is higher than that of HOY FDY or SDY FDY under the same condtions. All FDY showed the highest dye pickup rate at $100^{\circ} \mathrm{C}$. In the FDY produced at high first G/R speed by

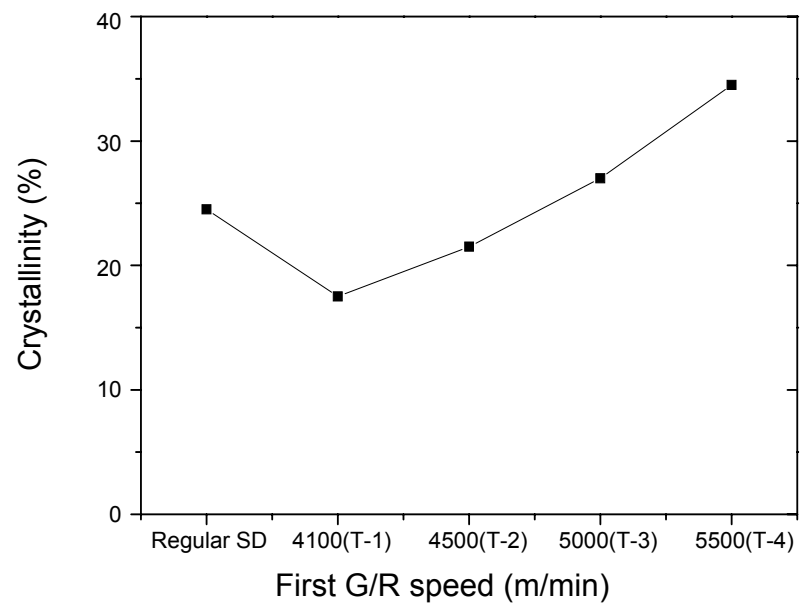

Figure 7. Crystallinity of polyester FDY prepared with various first $G / R$ speed.

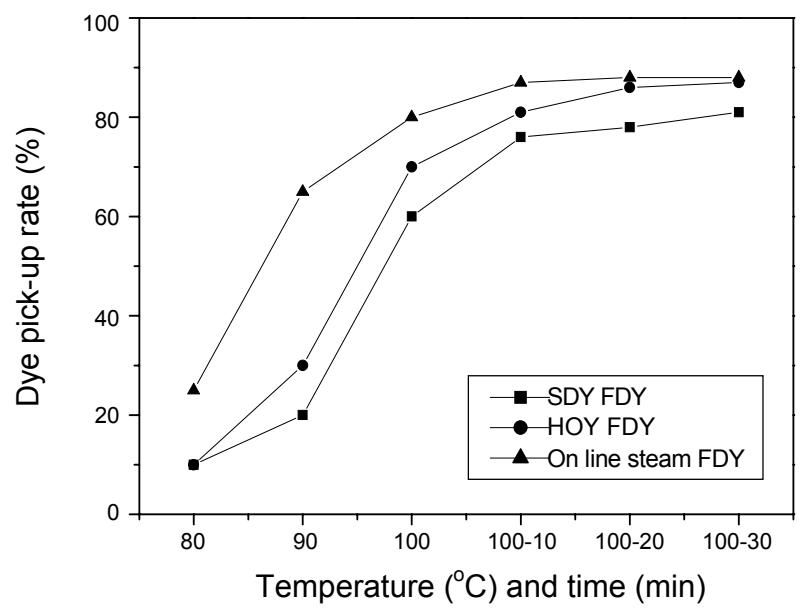

Figure 8. Dye pick-up rate of polyester FDY prepared with different spinning conditions as functions of temperature and time.

on-line steam processing, the internal crystal size and the amorphous region around the crystals increased; thus, the dye absorption was easily inceased.

Figure 9 shows K/S values of spin-draw and high-speed polyester FDY at different dyeing temperatures. As shown in the figure, the dyeing characteristic of high-speed FDY without a carrier is higher than that of regular FDY. Regular FDY showed a low dyeing characteristic at a dyeing temperature of $130^{\circ} \mathrm{C}$, as 
(a)

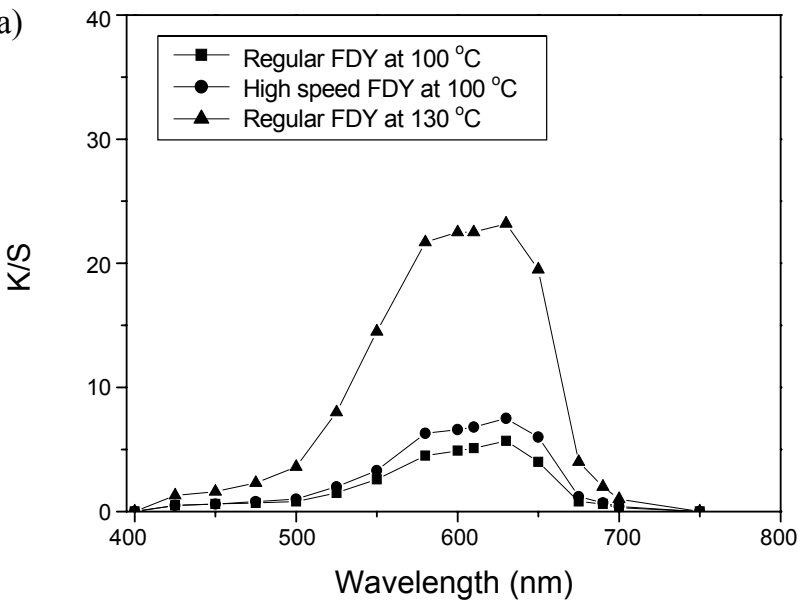

(b)

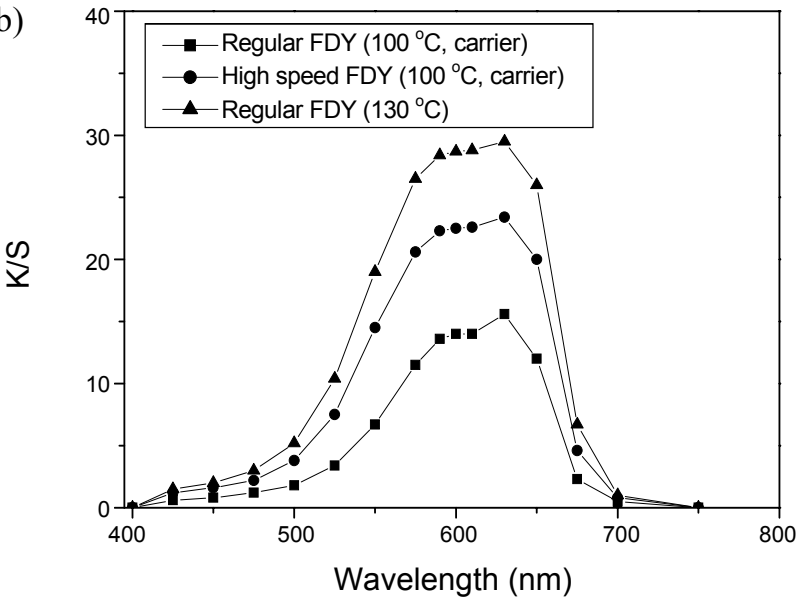

Figure 9. K/S values of spin-draw and high-speed polyester FDY at different dyeing temperatures: (a) without carrier, (b) with carrier.

shown in Figure 9 (a). As shown in Figure 9 (b), the K/S value of high-speed FDY with a carrier at a dying temperature of 100 ${ }^{\circ} \mathrm{C}$ is lower than that of regular FDY at $130{ }^{\circ} \mathrm{C}$, which indicates an excellent propensity for dyeing. This dyeing characteristic results in a high amount of dye absorption and an increase in the percentage of the yarn's internal amorphous region (or an increase in the unit size of the amorphous region). In addition, there is an increase in the amount of dye absorption per dyeing site in the amorphous region resulting in a deeper color. ${ }^{17}$

\section{Conclusions}

The effects of spinning conditions on the properties of polyester FDY prepared using an ultra-high-speed melt spinning technique were investigated. The values of wet shrinkage, crystallinity, $\Delta \mathrm{H}_{\mathrm{m}}$, and $\Delta \mathrm{H}_{\mathrm{c}}$ varied significantly at a spinning speed of around $4000 \mathrm{~m} / \mathrm{min}$. Elongation increased, and Young's modulus and birefringence decreased as the spinning temperature was increased. Tenacity decreased and elongation increased when the draw ratio was decreased or the first G/R speed was increased. The tenacity of polyester FDY increased and shrinkage decreased with increasing steam pressure. Crystallinity increased as the first G/R speed was increased. The K/S value of polyester FDY with or without a carrier was higher than that of regular FDY, which indicates an excellent dyeing characteristic.

\section{References}

1. Slattery, J. C.; Lee, S. H. J. Non-Newtonian Fluid Mech. 2000, 89, 273.

2. Slattery, J. C. Advanced Transport Phenomena; Cambridge University press: New York, 1999.

3. Kolb, R.; Seifert, S.; Stribeck, N.; Zachmann, H. G. Polymer 2000 , 41, 2931.

4. Kim, J. S.; Kim, S. Y. J. Appl. Polym. Sci. 2000, 76, 446.

5. Huang, H.; Tucker, P. A.; Cuculo, J. A. Polymer 1997, 38, 1101.

6. Pennings, A. J.; Kiel, A. M. Kolloid-Z und Z. Polymere 1965, 205, 160.

7. Yeh, G. S. Y. Polym. Eng. Sci. 1980, 20, 395.

8. Kamide, K.; Kuriki, T.; Manabe, S.; Iwata, M. J. Textile Machinery Sco. (Japan) 1985, 38, 27.

9. Choi, K.; Spruiell, J. E.; White, J. L. J. Polym. Sci., Polym. Phys. Ed. 1982, 20, 27

10. Kim, H. S.; Cho, H. H.; Ito, H.; Kikutani, T.; Okui, N. Seikei-kakou $1997,9,449$.

11. Bang, H. J.; Kim H. Y.; Jin, F. L.; Park, S. J. Bull. Korean Chem. Soc. submitted for publication.

12. Jin, F. L.; Park, S. J. Bull. Korean Chem. Soc. 2009, 30, 334.

13. Wu, G.; Li, Q.; Cuculo, J. A. Polymer 2000, 41, 8139.

14. Fonseca, V. M.; Fernandes, V. J.; de Carvalho L. H. J. Appl. Polym. Sci. 2005, 94, 1209.

15. Grasser, W.; Schmidt, H. W.; Giesa, R. Polymer 2001, $42,8517$.

16. Park, T. J.; Yu, S. H.; Cho, H. T. J. Korean Fiber Soc. 1998, 35 , 781.

17. Woo, J. B.; Park, J. Y.; Park, J. C.; Park, Y. H.; Chang, D. H. Proceedings of 2nd Asian Textile Conference 1993, 1, 424. 